\title{
Transmission Line on-line Monitoring System Based on Ethernet and McWiLL
}

\author{
Yujun Liu \\ Beijing Inspection and Quarantine Testing Center of \\ Beijing Entry-Exit Inspection and Quarantine Bureau \\ 100026 China \\ Hongyan Yin \\ Beijing Inspection and Quarantine Testing Center of \\ Beijing Entry-Exit Inspection and Quarantine Bureau \\ 100026 China
}

\begin{abstract}
Transmission line running status real-time monitoring can ensure the security of transmission line and reliable running. In this paper, by analyzing the existing problems of transmission line on-line monitoring communication system, the author proposes a transmission on-line monitoring communication solution that is based on industrial Ethernet and McWiLL. With the aid of highspeed industrial Ethernet technology and McWiLL broadband wireless communication technology, the high voltage induction electric, terminals and other aspects of technology, the system has realized the real-time monitoring of running status of transmission lines, satisfies the high speed transmission line on-line monitoring communication system, stable, reliable and secure transport requirements.
\end{abstract}

Keywords-transmission line on-line monitoring; Industrial Ethernet; McWiLL broadband wireless; High voltage induction electric

\section{INTRODUCTION}

Due to the transmission line safe and reliable operation has very important meaning for the development of smart grid, it is particularly important to monitor transmission lines running status. The characteristics of high voltage transmission line are long distance, large span, bad natural environment, big location difference and so on. In order to realize monitoring data reliable transmission over a long distance, transmission line on-line monitoring communication system should meet the following requirements: 1 . high communication speed, supporting the video/image transmission; 2. cover every monitoring spot; 3. long-distance transmission; 4. the ability of stable and reliable power supply [1]. Now mobile communication public network that is widely used in electric power communication and electricity private network can't meet the requirements of transmission line on-line monitoring system in coverage, bandwidth, reliability, security and other as pects. So combination of optical fiber and wire less technology to solve the problem of transmission line online monitoring, communication is becoming the transmis sion network development trend.

In this paper, by analyzing existing transmission line online monitoring communication scheme, the author puts forward a transmission line on-line monitoring system design based on fiber industrial Ethernet and McWiLL, analyzing this solution from the grid monitoring system design and the communication lin $\mathrm{k}$ design of transmission

\author{
Tong $\mathrm{Wu}$ \\ China National Institute of Metrology
}

line on-line monitoring, finally giving the monitoring terminal design.

\section{PRESENT SITUATION ANALYSIS OF \\ TRANSMISSION LINE ON-LINE MONITORING COMMUNICATION SOLUTION}

Existing communication solutions usually use the public mobile communication network GPRS/CDMA, 3G for remote access. Public mobile communication network can't cover some areas such as remote mountain area, desert area, etc, and its characteristics are poor scalability, high operating cost, low transmis sion rate, poor reliability, etc. So it is unable to meet the communication requirements of power transmission line on-line monitoring business [2,3].

Due to the wide use of OPGW [4], the use of optical communications and wireless technology to realize transmission line on-line monitoring is the only way to solve the problem. Optical communication technologies include EPON technology and optical fiber industrial Ethernet technology.

EPON technology has been used as the best choice for optical communication solutions [5,6]. But because of the communication distance between OLT and ONU is not more than $20 \mathrm{~km}$, when the transmission line between two substations is longer, distribution of monitoring points are scattered and the number is larger, it will cause more OLT serial number and few ONU number under OLT, affect the efficiency and reliability, it is difficult to meet the demand of monitoring.

The point-to point distance of optical fiber industrial Ethernet network is up to $80 \mathrm{~km}$, optical fiber industrial Ethernet network can use the existing OPGW with no operation cost, unsusceptible to environmental impact, high reliability, high real-time performance and high security. McWiLL broadband wireless access network integrating narrowband voice and broadband data has 15 Mbit/s throughput, especially is suitable for multiple types of data transmission. So for the cases that longer monitored transmission line between two substations, more scattered distribution and a large number, it will establish the monitoring communication system by using optical fiber industrial Ethernet and McWiLL network in this paper. 


\section{MONITORING SYSTEM DESIGN BASED ON INDUSTRIAL ETHERNET AND MCWILL}

\section{A. The design of transmission grid monitoring system}

Transmission line on-line monitoring mainly includes five parts, namely metro monitoring center, substation monitoring center, monitoring terminal, communication network, monitoring information, as it is shown in Fig. 1. Monitoring terminals including the commonly used sensors and cameras, timer/real time fin ish collecting equipments status information of transmission line conductors, ground, tower, and insulators, etc, and collecting the environment temperature, humidity, wind speed, wind direction, rainfall. McWiLL network sends them to tower with industrial Ethernet switches, then are sent to a nearby substation monitoring center by the optical fiber Ethernet, then the substation monitoring center send the gathered information to metro monitoring center, monitoring center analyzes running status of the transmis sion line, gives pre-alarm information in time, thus effectively prevents all kinds of accidents. This article focuses on transmission line on-line monitoring system under substation monitoring center.

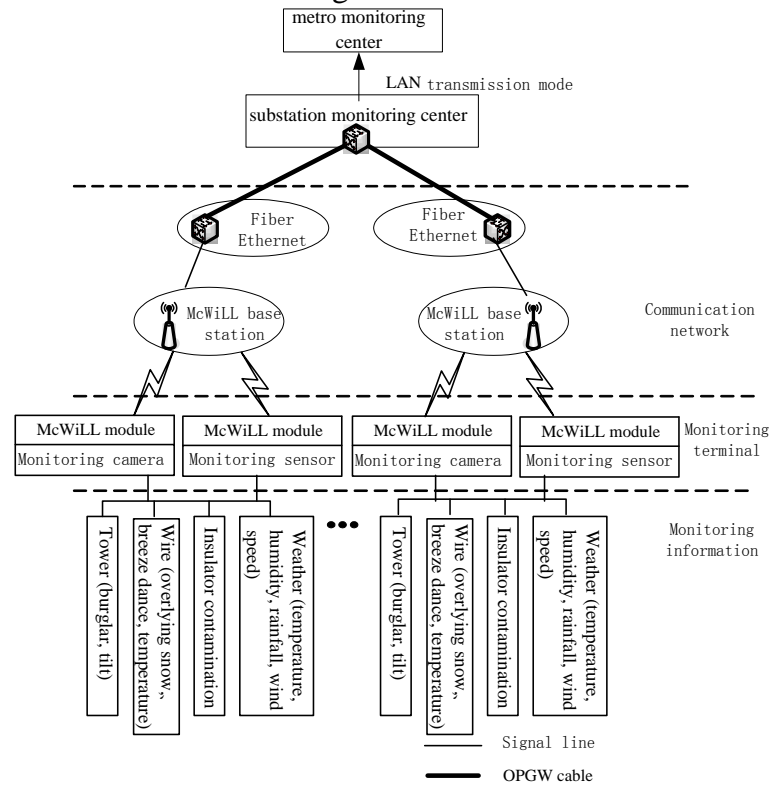

Figure 1. The overall block diagram of transmission line on-line monitoring

\section{B. The communication link design of transmission line on-line monitoring}

Monitoring stations locate in the transmission line and each tower, substation monitoring center need set up communication with each monitoring stations. The communication scheme that is put forward in this paper uses OPGW cable resources on the transmission line, combining industrial Ethernet and McWiLL broadband wireless access technology. It is characterized by high transmission rate, good reliability, wide coverage, long transmission distance, and no communication costs. As OPGW cable must be connected by a cable connecting box, so fiber Ethernet switch can only be placed in a tower with OPGW cable connecting box, the monitoring distance from the each terminal to the cable connecting box use McWiLL to communicate. Optical fiber Ethernet switches and McWiLL base stations are placed on towers with OPGW cable connecting box, McWiLL monitoring terminals are placed on the towers without OPGW cable connecting box, so it can realize the monitoring of full coverage. The communication architecture of the on-line monitoring systemis shown in Fig. 2.

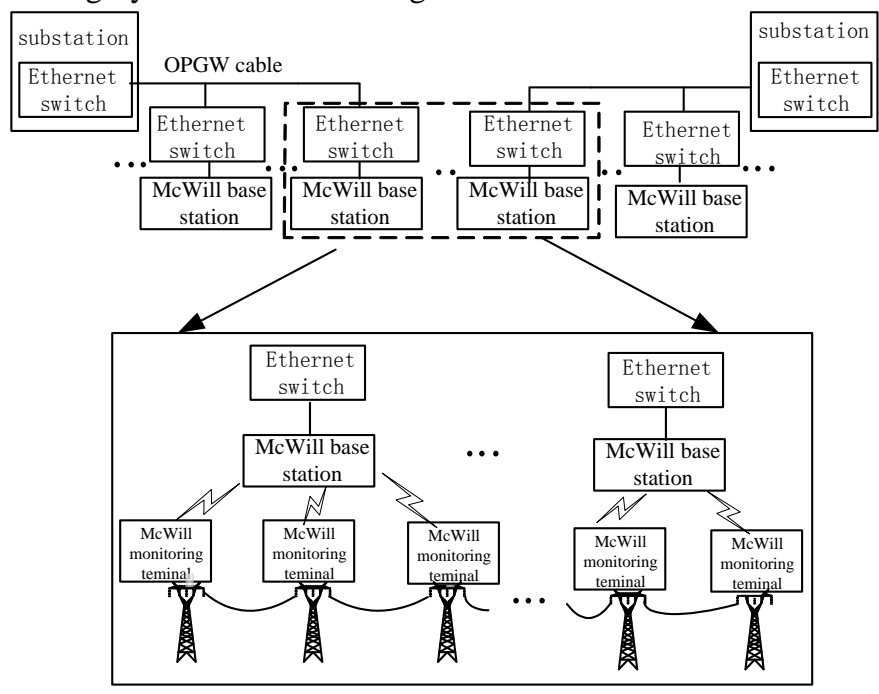

Figure 2. Online monitoring communication system architecture

1) Industrial Ethernet devices: Industrial Ethernet switches are placed in the transformer substations and the towers with the OPGW cable connecting box. Industrial Ethernet network support the transmission distance up to $80 \mathrm{~km}$, due to the limitation of McWiLL network transmission distance, starting from the substation, about each $10 \mathrm{~km}$ tower having OPGW cable connecting boxes is placed an Ethernet switch, due to the span of $110 \mathrm{kv} 220 \mathrm{kv}$ power transmission lines between each tower is $300 \mathrm{~m} \sim 500 \mathrm{~m}, 500 \mathrm{kv}$ transmission line between each tower is $500 \mathrm{~m} \sim 700 \mathrm{~m}$, so for $110 \mathrm{kv} 220 \mathrm{kv}$ power transmission lines, about every $20 \sim 30$ towers set an Ethernet switch, $500 \mathrm{kv}$ transmission line, about every 15 20 tower set an Ethernet switch. Ethernet switches in substation, connect power private network or monitoring master station via a gigabit Ethernet interface in the uplink, connect Ethernet switches of closest tower through another fiber gigabit Ethernet interface in the downlink, between adjacent Ethernet switches interconnect by using gigabit Ethernet fiber interfaces, thus form a logical Ethernet ring network, form hand in hand protection from the single point failure of an Ethernet switch or fiber broking of OPGW single point. Ethernet switches adopt double dc $12 \sim 18 \mathrm{~V}$ power to supply, ensure the reliability of power supply equipment.

2) McWiLL communication network: McWiLL base stations working in the $1800 \mathrm{MHZ}$ band coordinate with the smart antennas of $17 \mathrm{dBi}$ currently, the maximum coverage radius in the suburbs can be more than $20 \mathrm{~km}$. So McWiLL equipments can provide further down coverage for industrial Ethernet network. However, considering the 
transmission line transport environment, trends and transmission path loss, McWiLL base stations are placed in the towers with Ethernet switched, that is to say the towers about every $10 \mathrm{~km}$ having OPGW cable connecting boxes and industrial Ethernet switches is set on a McWiLL base stations, so a wireless connection establishes between the monitoring terminal and Ethernet switches. McWiLL base station us es 24/48V DC power supply.

3) The design of monitoring terminal: Monitoring terminals primarily are responsible for getting the condition monitoring data of obtaining transmission lines, towers, insulators and the surrounding environment, including line image / video, icing dancing, guided ground vibration, temperature and wires humidity, insulators contamination degree, tilt tower, micro weather (sunshine intensity, wind speed, etc.) and other monitoring data. Therefore, monitoring terminals include various types of sensors and cameras with McWiLL communication module [7,8], each monitoring point install the appropriate monitoring terminals according to the monitoring requirements, each terminal uses high voltage induction way of electric power supply.

Camera monitoring terminal is installed on each tower, and used to complete images and screen monitoring of the transmission lines surrounding environment and meteorology. The design block diagram of camera monitoring terminal is shown in Fig. 3, including CCD camera, encoding processor, MCU, McWiLL communication module and high voltage induction electric unit, etc. The camera will convert he video signal into a standard JPEG file by encoding processor, and the McWiLL communication module transmit the data to near McWiLL base station, McWiLL station will gather information and then send them to nearby the Ethernet switch through multiple hops, then Ethernet switch transmit the data to the substation monitoring center via OPGW cable, realize security, real-time, high-speed data communications with the monitoring center.

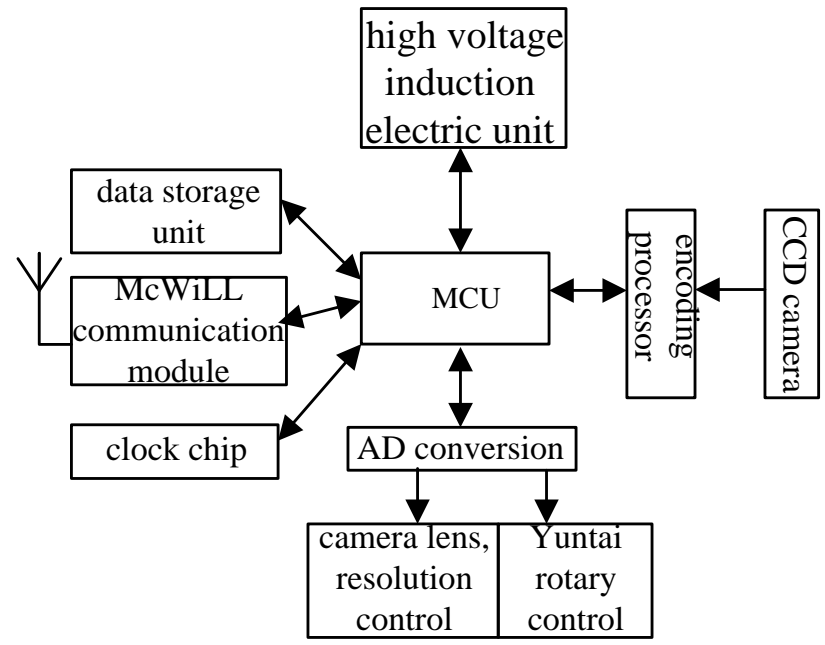

Figure 3. Block diagram of the camera monitoring terminal design

Sensor monitoring terminals mainly are installed in the transmission lines, are responsible for the monitoring of transmission lines operation condition and micrometeorology. Design block diagram of sensor monitoring terminal is shown in Fig. 4, mainly includes all kinds of sensor acquisition unit, the signal processing module, MCU, McWiLL communication module and high voltage induction electric unit. Data transmission mode is similar with the camera monitoring terminal transmission mode, so no further explanation.

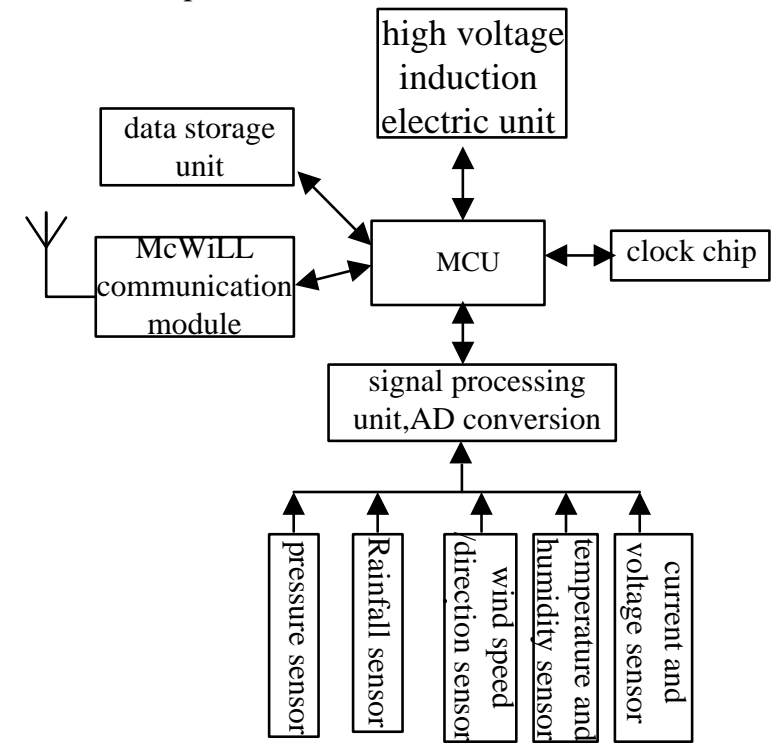

Figure 4. Design block diagram of sensor monitoring terminal

4) High voltage induction electric device: Since transmission line monitoring system online monitoring communication terminals and data transmission terminals are placed in the tower, the traditional power supply and solar power affected by the environment cannot provide continuous and stable power supply. Due to the unique in taking power style and design concept, high voltage induction electric device has features of adapting all kinds of bad weather is stable and reliable power supply all days, with long-term maintenance free operation, so as to overcome the shortcomings of solar power, which becomes the perfect choice for power of transmission line equipment. Therefore, using high voltage induction power system provides power for the monitoring terminal, ethernet switches and McWiLL base stations in the towers.

High voltage inductes electric device using electromagnetic induction principle, induces AC voltage from high voltage bus by taking energy coil, which then can be used as power supply after rectifier, filter, regulator.

\section{CONCLUSIONS}

Transmission line communication system based fiber Ethernet technology and McWiLL broadband wireless communication technology can achieve online monitoring of transmission lines between the two substations with longer transmission lines and more scattered distribution, can solve the monitoring data of transmission line conductors, ground, tower, and insulators and other equipment status information and the ambient temperature, humidity, wind speed, wind direction, rainfall and so on 
which is speed, stable, reliable and secure transmission problems. The design of communication system has important reference significance for construction of the transmission line condition monitoring system.

\section{ACKNOWLEDGEMENT}

This work is supported by the national quality inspection service project under Grant 201410050.

In order to mitigate noises and interferences in the transmission on-line monitoring communication systems, we used the commercial software titled "SmartSignalProcessing". This software is developed by Prof. Ming-Yue ZHAI from North China Electric Power University.

\section{REFERENCES}

[1] Wang Wei, Zhang Hao, Guo Jinghong. EPON-based transmission line condition monitoring data transmission system [J]. Electric Power Systems, 2011, 32 (225): 20
[2] V.C.Gungor,F.C.Lambert.A Survey on Communication Networks for Electric System Automation. Computer Networks, 2006, (50):877-897.

[3] Li Zhe, Liu Pingxin, Ge Min. The research transmission line monitoring system [J]. Communications technology, 2012,10 (45): 92.

[4] JIAO Xiao-bo, ZHOU Ya, LI Hong-jun. Application and development of OPGW cables in power optical transmission net work [J]. Study on Optical Communications, 2010(4): 49-51.

[5] Zhang Hao, Bo xiande, Guo Jinghong. The application of the EPON technology in power-expenditure information acquisition system [J]. Electric Power Systems, 2010, 31 (7): 42 45

[6] YIN Xiang-dong, The application of EPON technologyin remote communication of electricity utilization information collection[J]. Telecommunications for Electric Power System, 2010, 31(9): 3640.

[7] Liu Xu, Qi Bing, Sun Yi, Lu Jun. McWiLL wireless broadband remote reading system [J]. Electric Power Systems, 2009, 30 (204): 16

[8] Zhang Yuhua, Jia Limin, Li Zhong. wide range, multi-type data transmission system design based McWiLL [J]. Jilin University, 2011, 29(5): 409 410. 